\title{
EFECTO INHIBITORIO DE LOS TANINOS DEL FRIJOL CARIOCA (Phaseolus vulgaris L.) SOBRE LA DIGESTIBILIDAD DE LA FASEOLINA POR DOS SISTEMAS MULTIENZIMÁTICOS ${ }^{1}$
}

\author{
Victoria H. Del PINO², Franco M. LAJOLO ${ }^{2, *}$
}

\begin{abstract}
RESUMEN
Cantidades variables de dos sistemas multienzimáticos de tripsina-quimotripsina-peptidasa y pepsina-pancreatina, fueron utilizados para evaluar el efecto de los taninos provenientes de frijol Carioca (Phaseolus vulgaris L.) sobre la digestibilidad de la faseolina, en las formas nativa y denaturalizada. Esta evaluación hecha por los métodos de caida de $\mathrm{pH}$, de hidrólisis en medio tamponado con posterior medición del grado de hidrólisis con ninhidrina y por la técnica electroforética, demostró el efecto adverso de los taninos condensados sobre la digestibilidad de la faseolina, después de producirse una significativa inhibición en el grado de hidrólisis de esa proteina por los dos sistemas multienzimáticos. Se comprobó la dificultad de hidrólisis de la faseolina cuando esta unida al tanino en el punto de saturación (proporción 5/20 tanino/proteína p/p y mayores), después de detectarse en los perfiles electroforéticos, péptidos de 45.7 y $24 \mathrm{KDa}$, resistentes a la hidrólisis hasta por prolongados períodos de incubación. Esto se debió a la existencia de un complejo de naturaleza refractária no digeríble, incluso en condiciones excesivas de enzima. Los resultados sugieren la unión simultánea del tanino con mas de un ligante a través de sus múltiples grupos hidróxilos libres, formando un complejo proteina-tanino-enzima (PTE)* que correspondería a la fracción no digerible de la faseolina.

Palabras clave: Taninos; faseolina; digestibilidad; frijol; complejos tanino-proteina .
\end{abstract}

\section{SUMMARY}

INHIBITORY EFFECT OF CARIOCA BEAN TANNINS ON PHASEOLIN DIGESTIBILITY ASSESSED BY TWO MULTI-ENZYMATIC SYSTEMS. Variable amounts of the two multienzymatic systems, trypsin-chymotrypsin-peptidase and pepsin-pancreatin, were utilized for evaluating the effect of Carioca's bean tannins on the digestibility of native and denatured phaseolin. Three methods were used for this evaluations: the $\mathrm{pH}$ drop method, measurement of degree of hydrolysis by the ninhidrin reaction, and by electrophoretic techniques. The results showed the adverse effect of condensed tannins on phaseolin digestibility, for the two multienzymatic systems. Ours results strongly indicate that phaseolin is dificult to be hydrolysed when saturated with tannins $(5 / 20$ tannin/protein ratio w/w or higher). Resistant peptides of $45.7 \mathrm{KDa}$ and $24 \mathrm{KDa}$, that remained intact even after prolonged digestion were detected. This was due to the presence of very resistant tannin/protein complexes, which were not hydrolysed even at high enzyme concentrations. These results suggested the simultaneous reaction of tannins in a specific manner with more than one site on the protein, forming a protein-enzyme-tannin complex $\left(\mathrm{PTE}^{*}\right.$ ) producing an undigestible phaseolin fraction.

Keywords: Phaseolin; digestibility; beans; tanin-protein complexes.

\section{1-INTRODUCCIÓN}

Los frijoles (Phaseolus vulgaris L.) son leguminosas comunmente consumidas en grandes cantidades en Brasil y en el mundo. Estudios de fraccionamiento de la proteína del P.vulgaris $L$. han generado tres fracciones de proteínas solubles: la faseolina o globulina $G_{1}$, la globulina $\mathrm{G}_{2}$ y la albúmina, siendo la faseolina la más abundante proteína de reserva del frijol (36-46\%).

La utilización de las proteínas en animales y humanos es afectada adversamente por los taninos condensados, presentes en la cáscara de los frijoles, encontrándose en semillas secas entre $0-2 \%$, variando según la espécie y el color de la cáscara [5, 9]. Este efecto adverso de los taninos se deriva de la habilidad de asociarse y precipitar proteínas [2] mediante interacciones hidrofóbicas $[8,11]$ y por puentes de hidrógeno [11].

El principal objetivo de este trabajo es determinar el efecto de los taninos condensados sobre la digestibilidad de la faseolina del frijol Carioca (Phaseolus vulgaris L.), en las formas nativa y desnaturalizada, en sistemas

\footnotetext{
1. Recebido para publicação em 20/04/2001. Aceito para publicação em 24/04/2002.

2. Departamento de Alimentos y Nutrición Experimental, Facultad de Ciencias Farmacéuticas, Universidad de São Paulo Casilla Postal 66083, São Paulo, CEP 05315-970, Brazil.

* A quem a correspondência deve ser enviada.
}

modelo conteniendo faseolina, procianidinas y cantidades variables de enzima.

\section{2-MATERIALES Y MÉTODOS}

\section{1-Frijol}

Fue estudiado el frijol variedad Carioca (Phaseolus vulgaris L.) adquirido en los supermercados de la ciudad de São Paulo. Posteriormente, los taninos fueron extraídos de las cáscaras del frijol y purificados según HAGERMAN \& BUTLER [1], entre tanto para la obtención de la faseolina, fueron utilizados los cotiledones sin cáscara y luego, la proteína fué aislada según MC LEESTER et al. [6].

\section{2 - Enzimas utilizadas}

- Tripsina de páncreas de puerco tipo III (T-8253, Sigma), 12.000 BAEE unidades/mg de proteína.

- Quimiotripsina de páncreas bovino tipo II, (C-4129, Sigma) com 50 unidades/mg de polvo .

- Peptidasa de intestino de puerco (P-7500, Sigma) com 115 unidades/g.

- Pepsina de mucosa gástrica porcina, (P-7012, Sigma)

- Pancreatina de páncreas de puerco, tipo VI (P-1750, Sigma). Actividad 4 x U.S.P. specifications. 


\section{3 - Métodos}

Fueron utilizados dos sistemas enzimáticos: un sistema multienzimático de Tripsina-QuimiotripsinaPeptidasa y un sistema secuenciado de PepsinaPancreatina [7].

\subsection{1 - Sistema multienzimático de tripsina- quimiotripsina-peptidasa}

a) Formación de los complejos tanino-proteína para los ensayos in vitro

Investigaciones preliminares en este trabajo indicaron que el punto de saturación de la faseolina por el tanino (p/p), o cantidad de tanino que hizo precipitar toda la proteína en solución, fué la proporción $5 / 20$ tanino/ faseolina (p/p) y mayores, en la forma nativa, y de $3 / 20$ tanino/faseolina $(\mathrm{p} / \mathrm{p})$ y mayores, en la forma desnaturalizada $\left(100^{\circ} \mathrm{C}\right.$ por $\left.10 \mathrm{~min}.\right)$.

Tomándose en consideración tales proporciones, fueron formados los complejos en el punto de saturación a partir de alícuotas de $2 \mathrm{~mL}$ de una solución de faseolina en cloruro de sodio a $2 \%(\mathrm{pH} \mathrm{4,6)} \mathrm{conteniendo} 6,25 \mathrm{mg}$ de proteína, siendo colocados en tubos de ensayo plásticos y luego se adiciona el tanino; a continuación los complejos fueron mantenidos durante 15 minutos en el ultrasonicador. Después de ese tiempo, las mezclas fueron centrifugadas a $3500 \mathrm{rpm}$ durante 15 minutos, y posteriormente fue separada la solución sobrenadante cuidadosamente.

Los complejos con faseolina desnaturalizada fueron obtenidos después de mezclar la faseolina en solución acuosa de cloruro de sodio (2\%) con el tanino en frío (en el punto de saturación), y calentados juntos por diversos períodos de tiempo.

b) Digestibilidad in vitro de los complejos tanino/ faseolina

Con la finalidad de observar en sistemas in vitro el efecto de los taninos sobre la digestibilidad de la faseolina, fueron utilizados los métodos de caída de $\mathrm{pH}$ según HSU et al. [3] e hidrólisis en medio tamponado con posterior medición del grado de hidrólisis con ninhidrina según SPIES [9]; utilizando en ambos casos el sistema multienzimático de tripsina/quimiotripsina/peptidasa propuesto por HSU et al. [3], a una proporción enzima:substrato de 1:10. Este procedimiento fue repetido en condiciones excesivas de enzima, correspondiente a una proporción de 1:2 enzima:substrato.

\subsection{2 - Sistema pepsina-pancreatina}

a) Digestibilidad in vitro de los complejos tanino/ faseolina

La hidrólisis enzimática de los complejos tanino/ faseolina fue hecha de la siguiente manera:

Faseolina en solución acuosa de $\mathrm{HCl} 0.1 \mathrm{M}(\mathrm{pH}$ 2) a una concentración de $18.75 \mathrm{mg} / \mathrm{mL}$ fue sometida a calentamiento a $100^{\circ} \mathrm{C} \times 15 \mathrm{~min}$. Después de la desnaturalización de la proteína, $1 \mathrm{~mL}$ de este substrato fué colocado en diferentes tubos de ensayo y luego se adiciona tanino en polvo en una proporción 5/20 (tanino/proteína $\mathrm{p} / \mathrm{p}$ ). Seguidamente, los tubos fueron colocados en baño maría sobre agitación suave a $37^{\circ} \mathrm{C}$ por $15 \mathrm{~min}$. Inicialmente, éstas muestras fueron hidrolizadas con Pepsina en una proporción de $1: 66,67$ a $37^{\circ} \mathrm{C} / 1 \mathrm{~h}$. Después de este período, el $\mathrm{pH}$ fué elevado por la adición del mismo volumen de buffer fosfato $0.2 \mathrm{M}(\mathrm{pH} 8)$ y se adicionó Pancreatina en una proporción 1:30 continuándose la hidrólisis a $37^{\circ} \mathrm{C}$ por diferentes intervalos de tiempo. La digestión fue interrumpida con ácido tricloroacético (TCA) a $7.5 \%$ para diferentes intervalos de tiempo. Después de la centrifugación (10000rpm x $15 \mathrm{~min}$ ), los sobrenadantes fueron colectados para la determinación del nivel de hidrólisis. Además de los complejos tanino/proteína, proporción $5 / 20 \mathrm{p} / \mathrm{p}$, los blancos fueron preparados, uno conteniendo sólo las enzimas (blanco-enzima) otro apenas la proteína (blancomuestra). Este procedimiento fué repetido a una concentración de enzima tres vezes mayor $(1: 10$ enzima:substrato).

Electroforesis SDS-PAGE, a una concentración de $12.5 \%$, también fue desarrollada según la técnica de LAEMMLI [4].

\section{3- RESULTADOS Y DISCUSIÓN}

\subsection{Digestibilidad in vitro de los complejos tanino- faseolina en condiciones limitadas de enzima}

\subsubsection{Sistema tripsina/quimotripsina/peptidasa}

a) Por el método de caída de $\mathrm{pH}$ :

De la Tabla 1, puede observarse una disminución significativa $(\mathrm{P}<0,05)$ en la digestibilidad de los complejos tanino-faseolina desde la proporción $3 / 20$ hasta la proporción 9/20 tanino/proteina ( $\mathrm{p} / \mathrm{p})$, en comparación con la faseolina en estado libre, tanto para las formas nativa como desnaturada por 15 minutos y 1 hora a $100^{\circ} \mathrm{C}$, respectivamente. Si considerásemos el nivel mayor de tanino/faseolina (proporción 9/20), el porcentaje de disminución de la digestibilidad en comparación com la faseolina libre sería de $9,05,5,43$ y $11,7 \%$ para los complejos con faseolina de la forma nativa, desnaturalizada por 15 minutos y 1 hora, respectivamente. De forma general, observando la Tabla 1, podemos afirmar que el grado de digestibilidad aumentó a medida que aumentaba el tiempo de cocción de la faseolina; entre tanto, a medida que la cantidad de tanino era aumentada a la faseolina en solución, la digestibilidad de los complejos disminuyó proporcionalmente.

b) En medio tamponado, por la medición del grado de hidrólisis con ninhidrina:

Con relación a los complejos tanino-faseolina en el punto de saturación (proporción 9/20 tanino/proteína), puede observarse claramente, en la Figura 1, el efecto inhibitorio de los taninos sobre la digestibilidad de la faseolina al verificarse una disminución en el grado de hidrólisis de 62, 61 y $67 \%$ para complejos con faseolina nativa y desnaturalizada por $15 \mathrm{~min}$. y 1 hora respecti- 
vamente, después de un período de 3 hs. de incubación. Análisis estadísticos demostraron la existencia de una diferencia significativa.

TABLA 1. Digestibilidad de la Globulina $G_{1}$ libre y ligada al tanino por la técnica de caída de $\mathrm{pH}$

\begin{tabular}{cccc}
\hline Proporción & \multicolumn{3}{c}{ Digestibilidad (\%) } \\
& & & \\
& & & \\
& & & \\
& & & \\
& & & \\
& & & \\
& & & \\
\hline Só $\mathrm{G}_{1}$ & 78.8 & 88.3 & 93.3 \\
& & & \\
\hline $3 / 20$ & 73.8 & 85.1 & 87.4 \\
\hline $5 / 20$ & 73.4 & 83.7 & 86.9 \\
\hline $7 / 20$ & 72.0 & 83.3 & 84.7 \\
\hline $9 / 20$ & 69.7 & 82.8 & 81.5 \\
\hline
\end{tabular}

* Diferencia significativa a un nivel de significancia de 5\% , entre la faseolina libre y los complejos tanino-faseolina en todos los tratamientos estudiados.

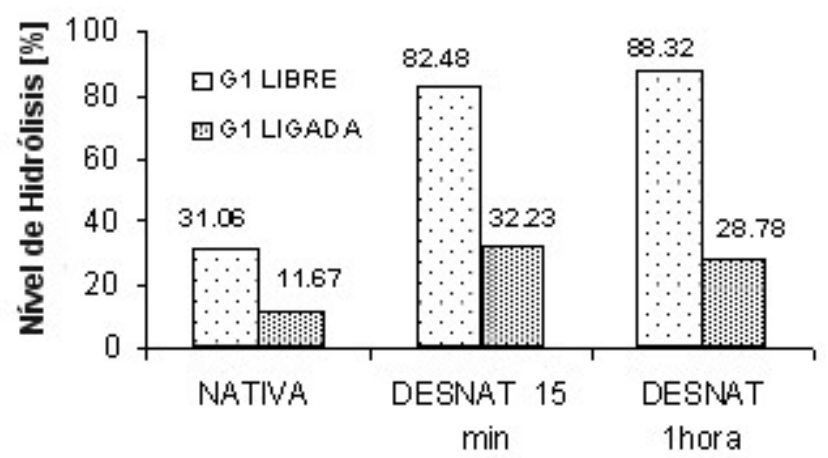

FIGURA 1. Digestibilidad in vitro de la G1 libre y unida al tanino en un sistema Tripsina-Quimiotripsina-Peptidasa.

La disminución en la digestibilidad fué mucho mayor en los complejos con faseolina previamente desnaturalizada por $1 \mathrm{~h}$ a $100^{\circ} \mathrm{C}$, probablemente debido a una mayor exposición de los grupos hidrofóbicos de la proteína, por el calor, a la acción de los taninos, los cuales se unen según $\mathrm{OH}$ et al. [8] básicamente a través de interacciones hidrofóbicas. Esta disminución en el grado de hidrólisis de la faseolina estudiada por los métodos, ya era esperada, pues extensa literatura trata del carácter inhibitorio de las procianidinas en la digestibilidad de las proteinas. Entre tanto, el mecanismo de acción de las procianidinas, en sistemas in vitro o in vivo, conteniendo proteínas como substrato $\mathrm{y}$ proteasas, aún no fue explicado.

Es muy importante llevar en consideración que la intensidad del efecto inhibitorio de los taninos varía según factores como la reactividad del tanino, el tipo de cultivo, el tipo de proteína a la cual se unirá, el grado de afinidad entre tanino y proteína, el $\mathrm{pH}$ del medio, la proporción tanino/proteína establecida en el momento de la unión y la variabilidad presentada por el método de medición utilizado.

\subsubsection{Sistema pepsina/pancreatina}

En la Figura 2, observase de forma general una disminución significativa en la hidrólisis de la Faseolina desnaturalizada cuando esta unida con el tanino en la proporción 5/20 tanino/proteina $(\mathrm{p} / \mathrm{p})$. Este efecto inhibitorio producido por los taninos, fué entre 41,5 y $65,2 \%$, después de comparar la digestibilidad de los complejos tanino-faseolina con la faseolina en estado libre.

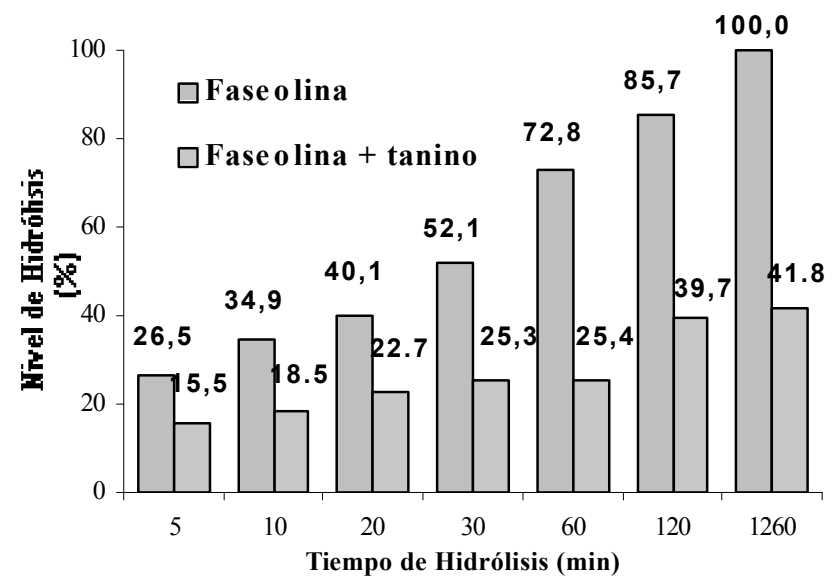

FIGURA 2. Digestibilidad in vitro de la G 1 libre y unida al tanino en un sistema Pepsina-Pancreatina. Proporción enzima/ substracto de 10:1.

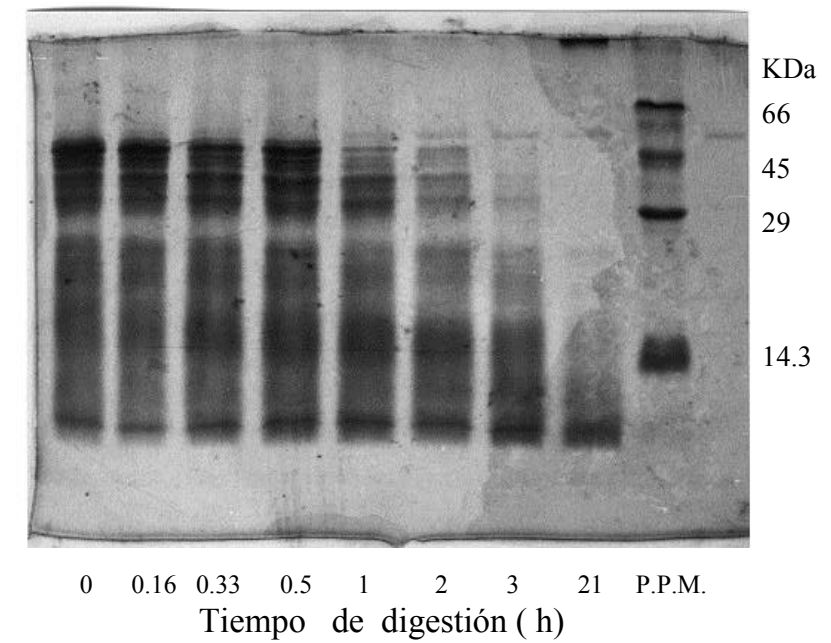

* El tiempo "0" corresponde a 1h de hidrólisis con Pepsina y los demás a la hidrólisis con Pancreatina.

FIGURA 3. Perfil eletroforético de los productos de hidrólisis de la faseolina libre y en diferentes tiempos de digestión.

Después de comparar la hidrólisis de la faseolina libre con la unida al tanino, se observó en los perfiles electroforéticos (Figuras 3 y 4 ), fuertes evidéncias de la dificuldad que presenta esta proteína a la hidrólisis cuan- 
do esta unida al tanino, luego de detectarse en los complejos tanino-faseolina péptidos de 45.7KDa y $24 \mathrm{KDa}$ resistentes a la hidrólisis hasta por prolongados períodos de incubación (21h). Situación diferente ocurrió con la hidrólisis de la faseolina libre, donde después de $2 \mathrm{hrs}$ de incubación fueron encontrados principalmente péptidos menores de 14,5KDa. Una de las causas atribuídas a la diminución de la digestibilidad de la faseolina es, probablemente, debida a las modificaciones conformacionales que los taninos podrian ocasionar en la molécula de la $\mathrm{G}_{1}$, dificultando el desarrollo normal de la proteólisis de la proteína.

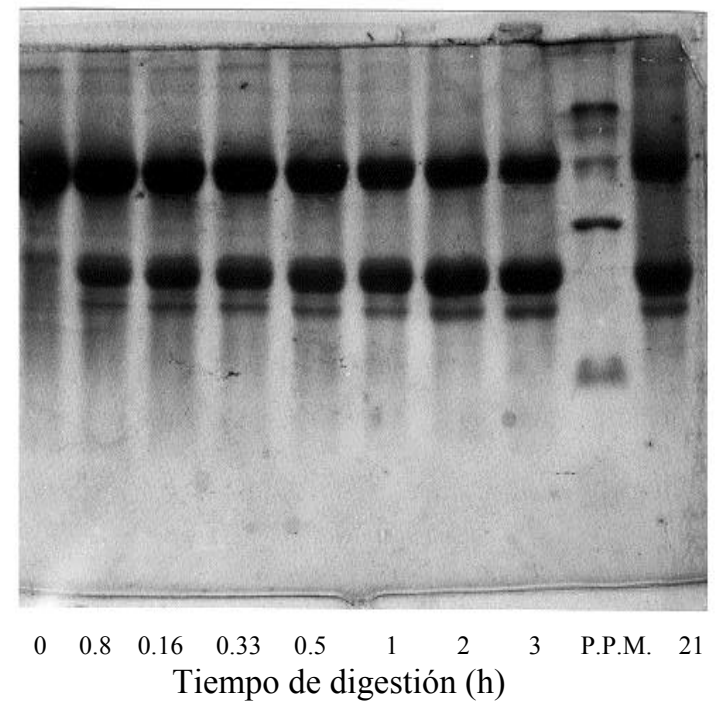

$\mathrm{KDa}$ 66 45 29

* El tiempo "0" corresponde a $1 \mathrm{~h}$ de hidrólisis con Pepsinay los demás a la hidrólisis con Pancreatina.

FIGURA 4. Perfil eletroforético de los productos de hidrólisis de la faseolina unida con el tanino y en diferentes tiempos de digestión. PPM = Padrones de Peso Molecular.

\subsection{Digestibilidad in vitro del complejo tanino- faseolina en condiciones excesivas de enzima}

\subsubsection{Sistema tripsina/quimotripsina/peptidasa}

En la Figura 5 se observó, conforme era esperado, el excesso de enzima causó un aumento en el grado de hidrólisis de la faseolina libre de 50 para las formas nativas y de 20 y $15 \%$ para las desnaturalizada, por $15 \mathrm{~min}$ y $1 \mathrm{~h}$ respectivamente, del valor encontrado en cantidad limitada de enzima. También se encontró (en la Figura 6) , un aumento en el grado de hidrólisis de los complejos tanino-faseolina de 39\% (forma nativa) y de 53 y $88 \%$ para formas denaturadas $15 \mathrm{~min}$ ou $1 \mathrm{~h}$ respectivamente, siendo que tal aumento fué directamente proporcional al grado de desnaturalización de la faseolina. Sin embargo, a pesar de que los complejos hayan aumentado el nivel de hidrólisis, aún el tanino demostró, bajo las condiciones de ensayo, su efecto inhibitorio, siendo de 65,$7 ; 50,3$ y $47,2 \%$ para las formas nativa $y$ desnaturalizada por $15 \mathrm{~min}$ y $1 \mathrm{~h}$, respectivamente.

Através de análisis estadísticos, se comprobó la existencia de una diferencia significativa $(\mathrm{P}<0.05)$ en los tratamientos de digestibilidad in vitro entre las proporciones $1: 10$ y $1: 2$ (enzima:substrato), tanto para la faseolina libre como para los complejos tanino-faseolina.

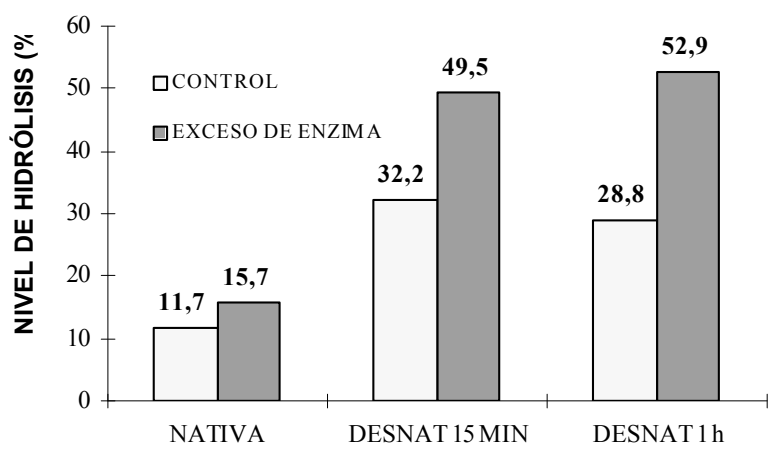

FIGURA 5. Aumento de la digestibilidad de la G 1 libre en condiciones de exceso de enzima. Sistema tripsina/ quimiotripsina/peptidase.

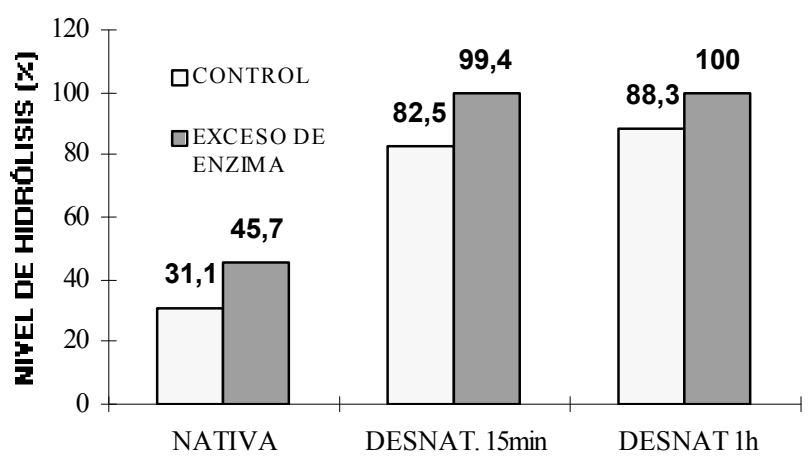

FIGURA 6. Aumento de la digestibilidad de la G 1 unida al tanino en condiciones de exceso de enzima. Sistema Tripsina/Quimiotripsina/Peptidase.

\subsubsection{Sistema pepsina/pancreatina}

En la Figura 7, se observó que, en cantidad excesiva de enzima (proporción 1:2), la faseolina en estado libre aumentó, conforme era esperado, su digestibilidad para los diversos tiempos de hidrólisis ensayados. Además, se encontró un aumento de 30 hasta $50 \%$ en la digestibilidad de los complejos tanino/faseolina en las condiciones de ensayo, observándose que ese aumento ocurrió en el período inicial de la hidrólisis (hasta $30 \mathrm{~min}$ ).

Con relación a este experimento en las concentraciones de enzima, es importante resaltar que, en esas condiciones de ensayo, el tanino aún presenta su efecto inhibitório, disminuyendo la digestibilidad de la faseolina de forma significativa entre $43.9 \%$ hasta $53.5 \%$ (hasta $180 \mathrm{~min}$ ) indicando que el effecto se debe a una acción de resistencia del complejo con el tanino mas que a la inhibición de las enzimas.

Los perfiles eletroforéticos de los complejos tanino/ faseolina en condiciones excesivas de enzima, fueron similares a los presentados anteriormente, observándose 
la dificultad que ellos presentan a la proteólisis, al encontrarse péptidos resistentes de 45.7KDa y 24KDa, que permanecieron intactos hasta por prolongados períodos de hidrólisis (21h).

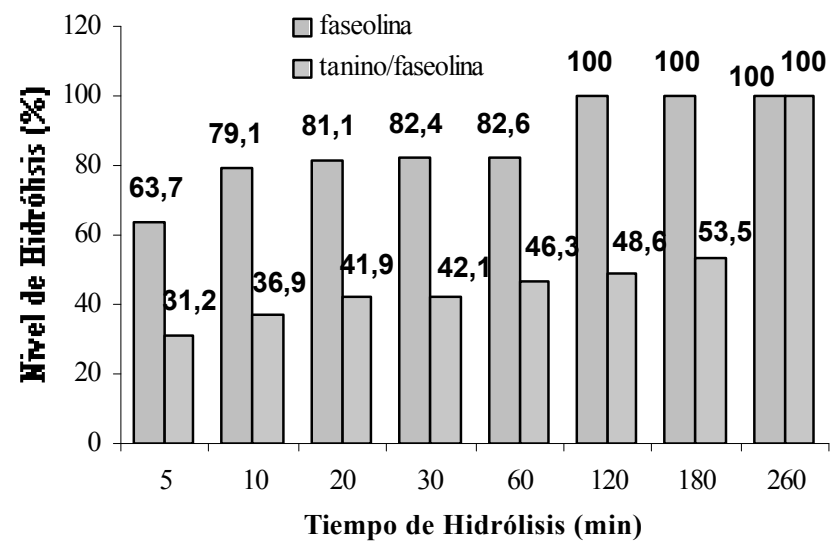

FIGURA 7. Digestibilidad de la G1 libre y ligada al tanino en condiciones de exceso de enzima: Sist. Pepsina-Pancreatina Proporción enzima/substracto de 10:1.

\section{4-CONCLUSIONES}

Los resultados obtenidos en este trabajo permitieron llegar a las siguientes conclusiones:

- La presencia de taninos condensados provenientes del frijol Carioca (Phaseolus vulgaris L.), afectaron la digestibilidad in vitro de la faseolina en sus formas nativa y desnaturalizada, cuando ésta estuvo unida al tanino en la proporción 5/20 tanino/proteína $(\mathrm{p} / \mathrm{p})$ el punto en el cual toda la proteína en solución era precipitada por los taninos, observándose una significativa inhibición en el grado de hidrólisis de esta proteína por los dos sistemas multienzimáticos estudiados de TripsinaQuimiotripsina-Peptidasa y Pepsina-Pancreatina., tanto en condiciones limitadas como en condiciones de exceso de enzimas.
- La presencia en los perfiles electroforéticos de péptidos de $45.7 \mathrm{KDa}$ y $24 \mathrm{KDa}$, resistentes a la hidrólisis hasta por prolongados períodos de incubación $(21 \mathrm{~h})$, evidenciaron también la dificultad que presenta la faseolina en ser hidrolizada en presencia de los taninos.

\section{5 -REFERENCIAS}

[1] HAGERMAN, A.E. \& BUTLER, L.G.- Condensed tannin purification and characterization of tannin-associated proteins. J. Agric. Food Chem., Washington, v.28, p. 947-952, 1980.

[2] HASLAM, E. \& LILLEY, T.H.- Natural astringency in foodstuffs-A molecular interpretation. CRC, Crit. Rev. Food Sci. Nutr., Cleveland, v.27, n.1, p. 1-40, 1988.

[3] HSU, 1977.

[4] LAEMMLI, U.K. - Cleavage of structural proteins during the assembly of the head of bacteriophage T4 . Nature, London, v. 277, p. 680-685,1970.

[5] MA, Y. \& BLISS, F.A.- Tannin content and inheritance in common bean. Crop Sci., Madison, v. 18, p. 201204,1978.

[6] Mc LEESTER, R.C.; HALL, T.C.; SUN, S.M.; BLISS, F.A Comparison of globulin proteins from Phaseolus vulgaris with those from Vicia faba. Phytochemistry, Oxford,v. 2, p.85-93, 1973.

[7] MILLER, G.A. - A multienzyme technique for estimating protein digestibility. J. Food Sci., Chicago,.v.42, n. 5, p. 1269-1273, 1977.

[8] OH, H.I.; HOFF, J.E.; ARMSTRONG, G.S.; HAFF, L.A. Hydrophobic interaction in tannin-protein complexes. J. Agric. Food Chem., Washington, v.28, p. 394-398, 1980.

[9] REDDY, N.R. \& PIERSON, M.D.- Dry bean tannins:A review of nutritional implications. J. Am. Oil Chem. Soc., Champaign, v.62, n.3, p. 541-549, 1985.

[10] SPIES, J.R. - Colorimetric procedures for amino acids. Methods Enzymol., New York, v. 3, p. 468-471, 1957.

[11] SWANSON, B.G. \& ARTZ, W.E. - Protein interactions with procyanidins. In: SCHWENKE, K.D., RAAB, B., eds. Interactions in protein systems. Berlin, Akademie-Verlag, 1989. p 115-127. (Proceedings of the 3rd. Symposium on Food Proteins, 1988). 